\title{
A New Paradigm for Virtual Knowledge Sharing in Product Development based on Emergent Social Software Platforms
}

\author{
Richard David Evans ${ }^{1}$, James Xiaoyu Gao ${ }^{2}$, Nick Martin ${ }^{3}$ and Clive Simmonds ${ }^{3}$ \\ ${ }^{1}$ Business Information Management and Operations, University of Westminster, London, UK NW1 5LS \\ ${ }^{2}$ Centre for Innovation Product Development and Manufacturing, University of Greenwich, Chatham
}

Maritime, ME4 4TB

${ }^{1}$ R.Evans@westminster.ac.uk, ${ }^{2}$ J.Gao@greenwich.ac.uk, ${ }^{3}$ Clive.Simmonds;

Nick.J.Martin@baesystems.com

\begin{abstract}
The UK Government considers its Aerospace Industry a remarkable success story, enjoying a global market share of $17 \%$ in 2015 . The capture, management and sharing of employee knowledge is seen as vital if the industry is to remain highly innovative and retain its pre-eminent position internationally. Aerospace manufacturers, such as BAE Systems, often have to re-engineer business processes routinely to ensure their survival. Knowledge sharing in the industry is seen as challenging due to the dispersed nature of its operations and multi-tier supply chains. This paper, through a five-year participantobservation study at the World's second largest aerospace and defence organisation, BAE Systems, proposes a new paradigm for virtual knowledge sharing in dispersed aerospace product development based on emergent social software platforms such as Enterprise 2.0 technologies. The developed framework and methodologies are applied to the bespoke BAE Systems' engineering lifecycle process to validate its effectiveness with results indicating that Enterprise 2.0 technologies offer a more openlyinnovative environment in which employees may share and interact with knowledge more effectively and
\end{abstract}


easily across geographical and functional boundaries, compared with conventional engineering information systems.

\section{Keywords}

Aerospace Manufacturing, Dispersed Product Development, Enterprise 2.0, Innovation and Knowledge Management, Knowledge Sharing, Virtual Teams.

\section{Introduction}

The 21st Century has been identified as a time of rapid innovation and technological advancement, with the last two decades being characterised by major developments in enterprise globalisation and technological advancement, particularly highlighted by the birth of the World Wide Web (WWW) and the introduction of Web 2.0 technologies such as micro-blogging (e.g. Twitter.com), social networking (e.g. Facebook.com) and web conferencing facilities (e.g. Skype). Building upon the underlying characteristics of Web 2.0 (e.g. user-generated and participant centred), Enterprise $2.0^{1}$ refers to Web-based collaborative technologies which companies may employ to allow them to make pre-existing knowledge and skills of workers more widely visible and shareable around the organisation. Enterprise 2.0 can facilitate the dismantling of organisational hierarchies and silos and allow for improved knowledge sharing between employees ${ }^{2,3}$. The term was first coined in 2006 by Professor Andrew McAfee ${ }^{1}$ of Harvard Business School who defined it as "the use of emergent social software platforms within companies, or between companies and their partners or customers". He stated that Enterprise 2.0 technologies should comprise six key functional elements, which he referred to under the acronym SLATES (Search, Links, Authoring, Tags, Extensions, Signals), as shown and described in Table 1.

Table 1: Six Key Components of Enterprise 2.0 (SLATES) 


\section{$\ll<<$ INSERT TABLE 1 ABOUT HERE $\gg \gg$}

The increased development and usage of such technologies in a business context has resulted in many opportunities being created for manufacturers worldwide, especially in the aerospace sector where it is often difficult to identify and locate individuals who possess highly specific expertise. Many manufacturers already appreciate the benefits of being more social in their work practices, acknowledging that Enterprise 2.0 allows for greater productivity, the generation of collective intelligence and collaborative innovation. By deploying Enterprise 2.0 technologies during Product Development (PD) projects, manufacturers are able to connect people to people and people to information; facilitate connectivity, sharing and collaboration across boundaries; capture a wide base of typically informal or highly dispersed views and information; help colleagues identify and locate previously unknown experts; and help employees discover organisational knowledge ${ }^{4}$. However, with opportunities, come numerous problems and challenges relating to openness in communication and lack of hierarchical control across geographical and functional boundaries. In an increasingly international marketplace, manufacturers need to develop flexible and responsive work practices to ensure survival ${ }^{5}$, while also introducing new systems and processes for successful innovation; the facilitation of enhanced employee and supplier collaboration across multi-tier supply chains; and the provision of opportunities for the development of employee skills and knowledge. A manufacturer's ability to create new products/services and innovative enhancements to existing ranges is seen as one of the strongest driving forces responsible for the sustained sale of manufactured products.

The ever-changing needs of customers are now driving manufacturers to introduce new products and services to their portfolio of offerings more frequently in order to sustain business, improve annual turnover and ultimately continue in existence. In introducing these new offerings to the marketplace, manufacturers have incorporated New Product Development (NPD) processes into their operational 
strategy, which aim to develop new concepts more effectively and efficiently ${ }^{6}$. In the case of BAE Systems' Electronic Systems, this process is known as the Engineering Lifecycle Framework (ELF). The ELF process is accomplished by following various phases of project definition-based tasks that primarily examine the right business opportunities and product concepts to meet potential or existing customer requirements. At the heart of this process is the product conceptualisation phase, which is facing numerous challenges that have emanated from the dramatic increase in data gathering and interpretation necessary to meet customer needs ${ }^{7}$. In addition, ongoing concept development programmes require manufacturers to respond to changes in the marketplace far more quickly, creating a need for improved customer insights during product conceptualisation and requiring deeper processing of available data from end-users in order to capture real-time information relating to changing needs and feedback, based on interactions with existing products. For purposes of clarity in this context, input is required both from the customer (i.e. the person/organization purchasing products/services) and end-users, i.e. those actually using the product/service ${ }^{8}$.

Nowadays, it is no longer sufficient for internal departments to simply work in cross-functional teams sharing ideas captured from the lessons learned and experience gained from previous projects. Manufacturers must now engage in real-time conversation with stakeholders during the PD process, including end-users and supply chain partners, utilizing current Web 2.0 technologies to communicate and identify recommended changes and enhancements to existing ranges. It is important for the success of any product development programme that stakeholder data and other business requirements are incorporated into its early stages ${ }^{9}$; Figure 1 illustrates the information capturing requirements of the product conceptualisation phase; these include 1) Data gathering, 2) Data and analysis and 3) Data appropriation, which form the process of capturing the front end requirements in a product development programme ${ }^{10}$. 


\section{<< INSERT FIGURE 1 ABOUT HERE $\gg>$}

Fig.1. Product Conceptualisation Process

As manufacturers aim to develop improved solutions in less time with reduced costs, the traditional PD process is deemed no longer sufficient. Successful PD relies far more upon greater corporate teamwork, with the 'team' being located internally and externally, often in dispersed locations and in different time zones. Such is the case with Boeing Corporation and its 787 aircraft, which is designed and manufactured across four continents and involves 14 independent original equipment manufacturers. In order to maintain and develop competitive positions, successful knowledge sharing during PD and the ability to innovate and introduce new product platforms and innovative enhancements to existing ranges are fundamental to success ${ }^{11}$. It is no longer sufficient to re-engineer product and service offerings; if companies wish to survive and prosper, they have to explore, exploit and retain their employee and corporate knowledge in order to sustain competitive advantage ${ }^{12}$.

Especially in relation to engineering and high technology sectors, such as the Aerospace Industry (AI), the effective management and sharing of knowledge is paramount ${ }^{13}$. Failure to achieve this can ultimately restrict access to key information, fail to address product defects and reduce opportunities for innovation. In the AI, design and manufacturing engineers are no longer simply required to possess the knowledge to fabricate products, such as civilian airplanes and combat aircrafts; they now have to develop their knowledge and skills to be proficient in the use of Computer Aided Design/ Manufacturing/ Engineering (CAD, CAM, CAE), Product Data Management (PDM) and Product Lifecycle Management (PLM) software and other knowledge-based systems ${ }^{14}$. Research ${ }^{15}$ has shown that engineers in PD teams are increasingly expected to work collaboratively across geographical boundaries and between multifunctional business units and multi-tier supply chains. In the case of the collaborating company, BAE Systems, the need for enhanced collaborative knowledge sharing is viewed as imperative. The company 
works with over 1250 independent suppliers in the UK alone, with 20,000 worldwide; on average, £10 billion is spent per annum on supplier integration. Additionally, with the advent of lean and agile manufacturing processes, the scope of PD has been extended to incorporate both client base and supply chain. The process now frequently involves multi-disciplinary groups including designers, engineers, manufacturing/technical specialists, customer representatives, supplier partners and third-party consultants, as illustrated in Figure 2.

\section{$<<<$ INSERT FIGURE 2 ABOUT HERE $\gg>$}

Fig.2. Multi-Tier Aerospace Supply Chain

\section{Knowledge Sharing via Web 2.0 in Aerospace Manufacturing}

In large, globally-dispersed aerospace manufacturers, such as BAE Systems, research has shown that creating a sustainable knowledge sharing culture is a highly complex task ${ }^{16}$; the working together of colleagues can never be guaranteed and companies must strive to facilitate team working to develop true competitive advantage. In dispersed organisations, employees often cannot identify what is known by other colleagues as it remains hidden in knowledge silos; consequently, best practices, expertise and knowledge and skills cannot easily be transferred. However, Web 2.0 technologies offer the prospect of transferring tacit as well as explicit knowledge in an easier and less-formalised method.

It is widely recognised ${ }^{14,16}$ in the AI that effective knowledge sharing is a key component of successful PD. In dispersed manufacturing teams, the capture and sharing of knowledge can offer many benefits, among which integrated PD is seen as key to enterprise process management. The integration of people, processes, information and knowledge through technology is fundamental to effective enterprise knowledge sharing ${ }^{17}$. Over the years, ICT systems have contributed to an explosion in the availability of 
knowledge stored within codified files. Now, however, research shows ${ }^{18}$ that engineers no longer wish, nor indeed have the time, to read through entire computer-based documentation; instead, they wish to acquire knowledge selectively from a variety of sources and media types, including Web 2.0 technologies which may embed video, imagery and other media types. PD teams must, therefore, optimise the capture and use of design ideas and concepts and collaborative Web 2.0 technologies currently being employed and developed can greatly assist with this. Furthermore, the geographical distribution of global virtual development teams frequently found in multi-national manufacturers demand the greater use of web 2.0based collaborative technologies.

Collaboration during PD often requires dispersed colleagues to communicate and work together to deliver innovative products and services. A distinguishing feature of a collaborative production environment is that the design and manufacturing functions, although dispersed, are often networked, well-integrated and work together effectively; in this regard, the WWW is fundamental. With the rapid growth in the use and popularity of Web 2.0-based technologies, knowledge exchange around the world has become easier and more common, with team members being able to work collaboratively and often simultaneously. To this end, it is proposed that knowledge originating from multiple sources may be effectively integrated within the PD process using designated knowledge management systems employing Web 2.0-based technologies.

\section{Aim and Method}

Against a background where aerospace manufacturers are seeking to enhance methods of knowledge sharing to meet PD targets while developing competitive advantage, it is believed that Web 2.0 technologies provide the means to contribute to such improvements. The aim of this research is to extend and adapt the research of McAfee ${ }^{1}$ by relating the SLATES paradigm to the bespoke engineering 
lifecycle framework PD process, developed, employed and refined within BAE Systems' Electronic Systems, and to present an Enterprise 2.0 framework, which formed the basis for the development of a previously reported Enterprise 2.0 groupware ${ }^{19,20}$.

The authors adopted a participant-observation approach to this research. From 2010-2013, the first author of this paper was employed as a PhD Researcher at BAE Systems' Electronic Systems division in Rochester, Kent, UK. From 2013-2015, he was employed as a Research Fellow working collaboratively with BAE Systems. During both periods, the supervision team consisted of Professor James Gao from the University of Greenwich and Nick Martin (Innovation and Growth Leader) and Clive Simmonds (Chief Engineer of Operations) from BAE Systems' Electronic Systems. Over the 5 year period, the first author acted as a participant-observer inside the company, gaining an in-depth understanding of the complex nature of the company's bespoke PD process by observing with ethnographic sensibility ${ }^{21}$. On a monthly basis, the first author would hold two hour long meetings with his supervision team to discuss collaboration and knowledge management issues experienced by his colleagues inside the company. On a biannual basis, the authors would present their findings to senior management of the Rochester site to formulate ideas and scope the development of the proposed framework and the developed collaborative groupware.

By immersing himself in the NPD facility, the first author was able to collect a large amount of data over the five year period through various methods, including observation, focus groups and online surveys. Results of several studies 4, 19, 22 inspired the development of the proposed framework from which a collaborative groupware was developed and validated ${ }^{3}$. 


\section{An Enterprise 2.0 Framework for Virtual Employee Knowledge Sharing}

The proposed Enterprise 2.0 Framework for improving employee knowledge sharing during the PD process is inspired by and seeks to build upon the work of McAfee ${ }^{1}$. While recognising that digital platforms, under the name of 'Web 2.0', were already popular on the WWW for generating, sharing and refining information, McAfee coined the term 'Enterprise 2.0' to provide a clear focus on the use of "emergent social software platforms" within companies. To this end, he highlighted that "platforms are digital environments in which contributions and interactions are globally visible and persistent over time" and emphasized that "emergent means that the software is freeform in so far as it means the software is most or all of the following: 1) Optional, 2) Free of up-front workflow, 3) Egalitarian, or indifferent to formal organisational identities, and 4) Accepting of many types of data, and as such, contains mechanisms to let the patterns and structure inherent in peoples interactions become visible over time" ${ }^{23}$. He provided a specific focus on something which could, in his opinion, be seen as strange technologies and technology-communities by many people; these included: blogs, wikis, social networking software and others, including prediction markets and so on. In other words, he provided a spotlight onto the opportunities on offer to organisations to make the practices and outputs of their internal and external knowledge workers more visible.

McAfee ${ }^{1}$ identified six key functional elements of Enterprise 2.0 and these consisted of Search, Links, Authoring, Tags, Extensions and Signals, otherwise known as SLATES, as presented in Table 1. At the heart of the framework proposed in this paper lie examples of the types of Web 2.0 technologies currently in common usage within BAE Systems. Surrounding these are the key elements identified by McAfee (SLATES) which form the inner focus of the framework; these emphasize the central role that Web 2.0 technologies are capable of playing during product development processes. In the proposed framework presented in Figure 3, SLATES are presented against a background where Customers, 
Suppliers, Employees and Other Stakeholders are able to input to the PD process through the use of Web 2.0 technologies which facilitate the creation of user-contributed content.

\section{$<<$ INSERT FIGURE 3 ABOUT HERE $\gg>>$}

Fig.3. Proposed Enterprise 2.0 Framework for Improving Virtual Employee Knowledge Sharing during PD

At this point, it is important to emphasize that Web 2.0 technologies are often selected and used arbitrarily by knowledge workers and are capable of facilitating collaborative PD processes in a less formal manner; this is the case at BAE Systems' Electronic Systems where employees select web 2.0 technologies independently when performing their roles, but lack corporate guidance on which to use for selective PD tasks. When BAE Systems' engineers were observed delivering the various functional requirements of their company's bespoke PD lifecycle process (ELF), it was concluded that 7 key actions were performed when collaborating to meet PD aims and objectives; these are defined as CRIIERS Actions - Communicate, Review, Investigate, Improve, Evaluate, Refine and Share. Enhanced generation, sharing and refinement of knowledge is being achieved during the ELF process through the use of Web 2.0 technologies which provide the functionality of the six key SLATES components of Enterprise 2.0 and facilitate the 7 key CRIIERS actions identified as being employed for effective PD.

It is self-evident that PD should remain an iterative process and collaborators are continually empowered by Web 2.0 to communicate and review ideas and opinions, develop concepts, analyse data, review and improve colleagues' contributions and provide direction to proposed development ideas in a relatively informal social environment ${ }^{3}$. Furthermore, both external and internal stakeholders are able to participate in collaborative processes with comparative ease, while knowledge may be shared and managed in a virtual global environment relatively unhindered by traditional perceived barriers, such as 
geography, cost, time and even animosity between individuals who may not interact well in face to face situations.

Enterprise 2.0 as a concept offers organisations the prospect of more powerful outcomes as individuals can use personal online practices to enhance commercial knowledge development without the typical constraints found in more traditional business environments. Global virtual teams may be encouraged to participate in PD processes in Enterprise 2.0 online communities with enhanced sharing of user-generated content being the outcome to the benefit of all; Jiang et al. ${ }^{24}$ identifies the recent introduction of the term 'social manufacturing' which extends the idea of crowdsourcing to enable manufacturers to communicate directly with stakeholders via decentralized social media platforms. The interaction of all of the elements described in the framework allows for the generation of more creative and innovative solutions in a farther-reaching informal environment.

When considering the use of the proposed Enterprise 2.0 framework within organisations, it is important to remember that this is a generic framework which is adaptable to bespoke PD processes. Furthermore, it should be noted that the framework describes a process or method of working which is different from more traditional practices - it still anticipates making use of the same initial information input available within global teams and enterprises but, significantly, processes are facilitated in a very different manner. The potential on offer, as outlined by the framework, is for enhanced knowledge generation as a result of collaborators being empowered and encouraged to generate and share more of their own content in the less formal, but potentially more powerful and creative environment of Enterprise 2.0 .

In the case of BAE Systems, observations showed that engineers were using Web 2.0 technologies on an ad-hoc personal basis, but lacked corporate guidance on which technologies may be most appropriate for meeting the needs of specific outcomes required during the ELF. The proposed framework conceptualises the potential on offer through the deployment of Web 2.0 technologies within 
organisations and seeks to promote their usage more widely by PD teams. It demonstrates how the needs of PD may be met more effectively through enhanced functional and communication facilitation via Web 2.0. Previously, as may be seen in Figure 4, the ELF is presented in a linear design with no reference to tools and methods to be employed, whereas the proposed framework in Figure 3, demonstrates the scope presented by Web 2.0 technologies to facilitate PD processes and, in particular, the ELF. Delivery of the proposed framework may be achieved through the development of bespoke or generic tools ${ }^{3}$.

\section{The Proposed Framework in Practice}

The central portion of the framework in Fig. 3 illustrates some of the key Web 2.0 technologies on offer to collaborators during the PD process. Through appropriate selection from the range of technologies and tools depicted in the central SLATES core, users are able to access the key components of SLATES and benefit from their functionality and capabilities. The functionality provided by Web 2.0 also allows collaborative workers to perform the key CRIIERS actions which are identified beyond the central core. Fundamentally, Web 2.0 allows users to:

- Communicate readily with an accessible record of data communicated;

- Review enterprise capabilities and data within a collaborative environment;

- Investigate concepts, opportunities and fresh input;

- Improve products and designs through the sharing and contribution of new information, knowledge, comments and ideas;

- Evaluate facts, figures and proposals prior to embarking upon further actions;

- Refine ideas, concepts and theories; and

- Share comments, thoughts and feedback more easily and informally. 
Key objectives for those involved in PD are to generate and screen ideas; develop and test concepts; analyse business and market opportunities; implement technical innovations and commercialise products through continuing constructive collaboration. It is against this background where the fundamental roles performed through CRIIERS actions, and facilitated by Web 2.0 tools, may be visualized; quite simply, they allow collaborators to communicate and review data and ideas, investigate and improve testing and analysis of concepts, evaluate opportunities, refine ideas and plans and share information, knowledge and skills more comprehensively. When attention is turned towards the generic product development process, which has seven commonly recognised steps and is denoted in the framework by the middle ring with arrows, it may be observed that the CRIIERS actions provide the essential linkage between Web 2.0 and PD activities and highlight the ability of Enterprise 2.0 to enhance the process. Finally, the outer ring demonstrates the globally-inclusive nature of Enterprise 2.0, which enable both internal and external stakeholders to be fully involved in the PD process.

In summary, the proposed Enterprise 2.0 Framework illustrates a new paradigm for operating in a virtual environment where the same information and ideas available at the start of traditional PD processes may be used more collaboratively to deliver more powerful outcomes; these result from the greater freedom offered in Enterprise 2.0 communities for collaborators to be more creative and spontaneous in the generation and sharing of new knowledge.

\section{Application of the Proposed Framework to BAE Systems}

Product development projects at BAE Systems follow a bespoke product lifecycle process called the Engineering Lifecycle Framework; this identifies a series of 5 stages with 13 separate maturity phases (Figure 4) that a product may go through during its lifecycle. Each maturity phase is seen as a key milestone or gateway through which the development activity must pass. There are clear expectations 
established for the transition from one phase to another and a pre-agreed range of deliverables have to be satisfied; such actions aim to guarantee a high level of consistency and quality in the development process. Essentially, the BAE Systems development process is a customised and extended version of the generic PD lifecycle. Not all phases are mandatory, although they are fundamental to the process and the criteria for passing from one phase to another should be documented, with deliverables representing the input criteria for the subsequent phase.

\section{$\ll<$ INSERT FIGURE 4 ABOUT HERE $\gg>>$}

Fig.4. Engineering Lifecycle Framework for a Product at BAE Systems (Courtesy of BAE Systems)

By substituting the 13 separate phases of the BAE Systems' ELF process for the generic PD process shown in Figure 5, it may be observed that all BAE Systems' potential ELF actions are again capable of facilitation through Web 2.0 technologies, which perform the key CRIIERS actions identified.

\section{$<<<$ INSERT FIGURE 5 ABOUT HERE $>>>$}

Fig.5. Enterprise 2.0 Framework applied to the BAE Systems PD Process

When considering the process in detail, it is possible to identify a comprehensive series of actions specified in the BAE Systems ELF and compare them with the key CRIIERS actions (Table 2). From this table, it is concluded that all BAE Systems potential ELF outputs are deliverable via the CRIIERS actions facilitated through Web 2.0 and this is consistent with the generic Enterprise 2.0 Framework. Consequently, it is hypothesised that the generic Enterprise 2.0 framework is readily transferrable to organisations employing bespoke PD processes developed from the generic model. It is apparent that the key actions of Communicate and Share are required elements throughout the BAE 
Systems PD process and other CRIIERS actions play key roles on a routine basis throughout the process. Accordingly, it is deduced that the Enterprise 2.0 framework is applicable to the BAE Systems product development process.

This conclusion is also reinforced by a detailed comparison of the CRIIERS actions against the BAE Systems' product maturity gateways, as observed in Table 2. During each Maturity Phase, there is abundant evidence of CRIIERS actions being performed by PD team members and Web 2.0 technologies are seen to be clearly capable of playing key roles during these interactions.

Table 2: Comparison of CRIIERS Actions with BAE Systems' Product Maturity Gateways $<<$ INSERT TABLE 2 ABOUT HERE $>>>$

Based upon the findings of research conducted during the participant observation ${ }^{4}$, which involved in-depth face-to-face interviews with 67 senior members of engineering and management staff within BAE Systems, it has proven possible to identify a set of recommended guidelines to inform those organisations which plan to introduce Web 2.0 technologies into their NPD activities. The guidelines, as shown in Table 3, have been produced following extensive analysis of staff opinions and views; this allowed a comprehensive understanding to be gained of the typical tasks and communication methods that manufacturing engineers within the collaborating company employ when working on NPD projects. The authors then studied the characteristics of the more popular Web 2.0 technologies available today and considered their relationship to the common tasks undertaken during the product development process; this allowed the characteristics and functionality of each technology to be correlated with the PD tasks in order to formulate the proposed guidelines. Finally, after further evaluation and review with the supervision team to confirm which technologies were relevant to the needs of the organisation, the guidelines were presented, discussed and refined with senior key stakeholders at biannual meetings; 
during these meetings, which were attended by 12 senior managers and took the form of brainstorming focus groups, the various technologies were explored and evaluated to determine their applicability and suitability for the improvement of enterprise product development practices.

Table 3: Recommended Guidelines for improving Collaboration and Knowledge Sharing during the Product Development Process using Web 2.0 Technologies $<<$ INSERT TABLE 3 ABOUT HERE $\gg>$

Given the nature of contemporary Web 2.0-based tools, which are continually evolving and being developed, it is not asserted that the guidelines are exhaustive in scope. However, it is believed that they provide an informed overview of the more common Web 2.0 technologies which can be employed to best effect to enhance collaborative and knowledge sharing practices within enterprises seeking to optimise their PD activities. By adopting the foregoing suggestions, organisations are able to improve practices and, consequently, create more value added designs and product/service offerings to satisfy ever-increasing commercial demands, ultimately resulting in competitive advantage.

\section{Conclusion and Future Work}

Engineering enterprises, especially in the aerospace and defence industry, mainly use conventional engineering information and communication systems to manage technological data and information that is more structured and static in nature. As knowledge and social communications become increasingly important in modern engineering enterprises, emerging and fast developing social media technologies have shown significant potential in complementing traditional engineering information technologies for managing more dynamic and unstructured engineering information and knowledge. 
Building on the author's prior work, an Enterprise 2.0 framework has been developed to demonstrate a new paradigm for collaboration and knowledge sharing during the product development process through the utilisation of emergent social software platforms including Web 2.0 technologies, which have been increasingly and widely used for social communications and connectivity. The framework was inspired by the work of McAfee ${ }^{1}$ and identifies seven key CRIIERS actions which provide linkage between interactive Web 2.0 technologies and traditional and bespoke product development processes. The proposed framework was conceptualised within a world leading aerospace company, BAE Systems’ Electronic Systems, to enhance its product development process and guidelines have been formulated to assist the various stakeholders in the product development process. Compared with traditional engineering information systems, which are often highly complex and require specialized knowledge to maintain and operate, the new paradigm, based on Web 2.0 technologies, provides much simpler usability and less formal communication methods for employees. The technologies suggested in the proposed framework typically require little financial input and active maintenance, providing an effective avenue for employee collaboration and knowledge sharing during the PD process.

Further research should be completed into the motivational factors which encourage engineers to interact with Web 2.0 technologies. It was identified that employees do not always interact readily with Web 2.0 and it would, therefore, be of significant value to profile the factors which encourage or discourage the use of Web 2.0 in PD environments; to this end, the question of gamification or endorsement of the contribution of others could also warrant further study. Another recommendation for further research is to explore and understand the extent to which Enterprise 2.0 technologies actually improve the performance and output of engineering and manufacturing project teams in a quantifiable manner. Key Performance Indicators (KPI) could be established for such work and these could be employed when Web 2.0 technologies are selected by users; such a KPI could be 'time taken for 
collaborative responses compared to time taken when using e-mail or other traditional forms of communication'.

\section{Acknowledgements}

This paper is based on work funded by the EPSRC under Grant No. EP/H501258/1 and BAE Systems' Electronic Systems Sector in Rochester, Kent, UK. The authors would like to thank all at BAE Systems Group for their support with this project. Any opinions, findings and conclusions expressed in this paper are those of the authors and do not necessarily reflect those of BAE Systems' Electronic Systems Sector, BAE Systems Inc. or BAE Systems Plc., the parent organisation.

\section{References}

1. McAfee AP. Enterprise 2.0: The Dawn of Emergent Collaboration. MIT Sloan: Management Review. 2006; 47: 1-10.

2. Lin BW. Knowledge diversity as a moderator: inter-firm relationships, R\&D investment and absorptive capacity. Technology Analysis \& Strategic Management. 2011; 23: 331-43.

3. Evans RD, Gao JX, Martin N and Simmonds C. Integrating Social Knowledge and Collaboration Tools into Dispersed Product Development. International Journal of Advanced Corporate Learning . 2015; 8: 20-7.

4. Evans RD, Gao JX, Martin N and Simmonds C. An Investigation into the Potential Use of Social Media Technologies to Improve the Product Development Functions within the Aerospace and Defence Industry. International Conference on Manufacturing Research. Aston Business School, Birmingham, UK2012, p. 718-23. 
5. Gunasekaran A, Tirtiroglu E and Wolstencroft V. An investigation into the application of agile manufacturing in an aerospace company. Technovation. 2002; 22: 405-15.

6. Gershenson JK and Stauffer LA. Taxonomy for design requirements from corporate customers. Research in Engineering Design. 1999; 11: 103-15.

7. Hozdić E. Smart factory for industry 4.0: A review. International Journal of Modern Manufacturing Technologies. 2015; 7: 28-35.

8. $\mathrm{Xu} \mathrm{Y,} \mathrm{Chen} \mathrm{G} \mathrm{and} \mathrm{Zheng} \mathrm{J.} \mathrm{An} \mathrm{integrated} \mathrm{solution} \mathrm{-} \mathrm{KAGFM} \mathrm{for} \mathrm{mass} \mathrm{customization} \mathrm{in}$ customer-oriented product design under cloud manufacturing environment. International Journal of Advanced Manufacturing Technology. 2015; 17: 1-17.

9. Eres MH, Bertoni M, Kossmann M and Scanlan J. Mapping customer needs to engineering characteristics: an aerospace perspective for conceptual design. Journal of Engineering Design. 2014; 25: 64-87.

10. Cooper R, Wootton A and Bruce M. Requirements capture as process of technology-market integration. International Journal of Technology Management. 1999; 17: 582-96.

11. Ottosson S. Dynamic product development - DPD. Journal of Technovation. 2004; 24: 207-17.

12. Grant RM. Toward a knowledge-based theory of the firm. StrategicManagement Journal Speciallssue. 1996; 17: 109-22.

13. Huang C and Lin S. Sharing knowledge in a supply chain using the semantic web. Journal of Expert Systems with Applications. 2010; 37: 3145-61.

14. Bertoni M and Chirumalla K. Leveraging Web 2.0 in New Product Development: Lessons Learned from a Cross-company Study. Journal of Universal Computer Science. 2011; 17: 548-64.

15. Mishra AA and Shah R. In Union Lies Strength: Collaborative Competence in New Product Development and its Performance Effects. Journal of Operations Management. 2009; 27: 324-68. 
16. McAdam R, O'Hare T and Moffett S. Collaborative knowledge sharing in Composite New Product Development: An aerospace study. Technovation. 2008; 28: 245-56.

17. Ahmad R, Yuqing F, Chaudhry I and Hamidullah. Collaborative Product Development in Extended Enterprise. Dept ofAircraft Manufacturing, Beijing University ofAeronautics and Astronautics. 2005: 1-6.

18. Liu S, McMahon CA and Culley SJ. A review of structured document retrieval (SDR) technology to improve information access performance in engineering document management. Computers in Industry. 2008; 59: 3-16.

19. Evans RD, Gao JX, Martin N and Simmonds C. Using Web 2.0-Based Groupware to facilitate Collaborative Design in Engineering Education Scheme Projects. In: IEEE, (ed.). International Conference on Interactive Collaborative Learning. Dubai, United Arab Emirates: IEEE, 2014, p. 397 402.

20. Evans RD, Gao JX, Owodunni O, et al. A Framework for improving the Sharing of Explicit Manufacturing Knowledge through Micro-Blogging. In: Springer, (ed.). International Conference on Advances in Production Management Systems. Ajaccio, France2014, p. 19-26.

21. Pader E. Seeing with an ethnographic sensibility: Explorations beneath the surface of public policies. New York, USA: ME Sharpe, 2006.

22. Evans RD, Gao JX, Woodhead S, Martin N and Simmonds C. An Investigation into Collaboration and Knowledge Management during Product Development in the Aerospace and Defence Industry. 4th INSTICC International Conference on Knowledge Management and Information Sharing. Barcelona, Spain: SciTePress, 2012, p. 113-8.

23. McAfee AP. Enterprise 2.0, version 2.0. 2006.

24. Jiang P, Leng J, Ding K, Gu P and Koren Y. Social manufacturing as a sustainable paradigm for mass individualization. Journal of Engineering Manufacture. 2016; 230: 1961-1968. 